\title{
$\begin{array}{ll}\text { Research Square } & \text { Preprints are preliminary reports that have not undergone peer review. } \\ \text { They should not be considered conclusive, used to inform clinical practice, } & \text { or referenced by the media as validated information. }\end{array}$
}

\section{Assessing the effects of exposure to a SARS-CoV-2 re-positive patient in healthcare personnel}

\section{Yoshihiko Ogawa ( $\nabla$ hikoichi.ogw@gmail.com )}

Department of Infectious Diseases, Sakai City Medical Center

\section{Koji Nishida}

Department of Respiratory medicine, Sakai City Medical Center

\section{Iwao Gohma}

Department of Respiratory medicine, Sakai City Medical Center

Kei Kasahara

Center for Infectious Diseases, Nara Medical University

Hisakazu Yano

Department of Microbiology and Infectious Diseases, Nara Medical University

\section{Research Article}

Keywords: SARS-CoV-2, COVID-19, healthcare personnel, PCR re-positive

Posted Date: September 10th, 2020

DOI: https://doi.org/10.21203/rs.3.rs-74695/v1

License: (c) (i) This work is licensed under a Creative Commons Attribution 4.0 International License. Read Full License

Version of Record: A version of this preprint was published at BMC Research Notes on November 7th, 2020. See the published version at https://doi.org/10.1186/s13104-020-05365-y. 


\section{Abstract}

Objective: To evaluate whether patients with COVID-19 who have tested re-positive with the PCR test for the SARS-CoV-2 virus are infectious is a challenge in the current circumstances. A follow-up survey was conducted with healthcare personnel (HCP) who were exposed to a patient whose PCR test results for SARS-CoV-2 were re-positive 18 days after the initial confirmation of negative PCR results.

Results: We studied a total of $15 \mathrm{HCP}$ who had contact exposures (15/15) and aerosol exposures (7/15). None of them tested positive for IgG against SARS-CoV-2 on blood examination. None of them had any symptoms during 10 days of active isolation. All PCR tests conducted using the nasopharyngeal swabs collected from the HCP on day 10 were negative. No apparent infection was found in any of the HCP who had contact exposure with and/or aerosol exposure from the patient whose PCR test results for SARSCoV-2 were re-positive 18 days after the initial confirmation of negative results of PCR tests for SARSCoV-2.

Trial Registration: No. 170, approved June $10^{\text {th }}, 2020$ by the ethics committee of Sakai City Medical Center.

\section{Introduction}

The spread of COVID-19is still on-going in various regions. However, a new problem in regions where the epidemic has already been recognized is that patients are testing positive with the PCR test after the posttreatment results were negative.

In our hospital, another problem regarding COVID-19 patients is that it is difficult to find a transfer destination for the patients in whom management required physical disposal of protective equipment. This primarily occurs after long-term management in intensive care units, because especially in long-term care facilities, the medical protective equipment is insufficient. Thus, we created a policy that for patients whose sputum and/or nasopharyngeal PCR test results for SARS-CoV-2 were negative when measured twice separately over 24 hours, we stopped the precautions against aerosol transmission. If the PCR test results were negative again after 72 more hours, we stopped the contact precautions for COVID-19 transmission as well. This "72 more hours" is based on the report that SARS-CoV-2 has been detected for up to 72 hours after application to surfaces such as plastic and stainless steel [1]. A patient (an 81-yearold woman) who met the abovementioned criteria was waiting for rehabilitation transfer; however, she presented with worsening heart failure, due to which we determined that intensive care was required. Due to the sudden change in symptoms, she underwent nasopharyngeal and sputum PCR testing for SARSCoV-2 again; the results were re-positive. Due to this, several HCP who had interacted with this patient had to be marked for active isolation, as recommended by the CDC [2]. We evaluated whether COVID-19 infection had occurred in the HCP.

\section{Material And Methods}


We identified the HCP who needed isolation in our hospital according to the CDC guidelines for asymptomatic HCP who are exposed to individuals with confirmed COVID-19 [2]. We also performed viral culture for the index patient at Nara Medical University, Nara, Japan. The patient consented to the testing. The exposed HCP themselves carried out active isolation at home, as recommended by the infection control team in our hospital. Before active isolation, qualitative tests for the COVID-19 IgG antibody from Abbott $^{\circledR n}$ (Illinois, USA) were performed for all. After isolation, the HCP self-reported their daily physical condition and body temperature; if any physical abnormality was noted, an outpatient consultation was conducted. PCR testing of a nasopharyngeal swab was performed for each HCP on the $10^{\text {th }}$ day after exposure. This study was approved by the Ethical Committee of Sakai City Medical Center.

\section{Results}

The index patient first developed COVID-19 symptoms 10 days before she was admitted to our hospital. She was diagnosed with COVID-19 using the PCR test for SARS-CoV-2 before admission. She needed ventilator oxygenation and was placed in the ICU soon after admission. During her clinical course, she was prescribed low-dose systemic steroid therapy $(0.8 \mathrm{mg} / \mathrm{kg} /$ day prednisone) for organized pneumonia and tracheotomy was performed. Approximately 26, 29, and 33 days after the first symptoms appeared, nucleic acid amplification tests for the specimen from lower respiratory tract of SARS-CoV-2 were performed; the results of all tests were negative. The patient was subsequently transferred to the general ward. On the 44th day of illness, she developed aspiration pneumonia and pulmonary edema and was placed in the ICU again. At that time (44th day of illness and 18 days after initial confirmation of negative results of PCR), the PCR tests for the specimen of lower respiratory tract and nasopharyngeal swab were performed again, and the results were positive. We also performed viral cultures for these specimens over a week, but the cultures were negative.

There were 15 HCP: 2 doctors, 10 nurses, one speech-language-therapist, and 2 physical therapists (Table I). Blood exams taken within 2 days of exposure showed negative IgG antibodies to SARS-CoV-2 in all subjects. None of the HCP who had been under active isolation reported any physical symptoms, including fever and respiratory difficulties, during the 10-day isolation period. All PCR tests performed using a nasopharyngeal swab obtained on the 10th day after the exposure were negative.

\section{Discussion}

Since the first cases were reported in China in December 2019, COVID-19 has become a global pandemic. However, despite the fact that COVID-19 cases are gradually decreasing in many countries, a new problem has arisen: a certain number of patients are testing re-positive when subjected to the PCR test [3]. To date, the risk factors and clinical characteristics of patients in whom PCR for SARS-CoV-2 turned to be re- positive are unclear [3-5]. The core issue posed by this phenomenon is determining whether the patients whose PCR test results are re-positive are infectious. Kang [3] stated that in 3.3\% of COVID-19 cases, the results of PCR for SARS-CoV-2 were re- positive after the patients were released from quarantine, and there were no additional infection cases arising from the re-positive patients. Thus, he 
concluded that the re- positive cases were not infectious. In addition, Wolfel et al. described that viral cultures were negative 8 days after the onset of COVID-19 symptoms in all the patients in their study [6]. In our study, despite the PCR tests being positive, the viral culture was negative in all tested specimens. Furthermore, all the HCP who did not wear recommended personal protective equipment showed no signs of infection such as fever and respiratory symptoms, and all the results of nasopharyngeal swab PCR tests were negative. Thus, the hypothesis that a patient with re-positive PCR is not infectious is plausible. However, it is easy to say that culture positive means that the samples are infectious, but it is important to note that culture negative cannot be said to be non- infectious. Moreover, there are many facts about this virus that are yet unknown, and it should be still necessary to maintain infection control policies from the viewpoint of preventing the spread of infection especially in medical institutions.

\section{Conclusion}

In conclusion, no HCP were infected by contact with and aerosol exposures to SARS- CoV-2 re-positive patients in our hospital.

\section{Limitation}

There were several limitations to this study. First, the sample size was small. However, we investigated not only PCR test but viral culture for the index patient. And we also investigated PCR tests, and antibodies twice for the exposed HCP. Second, there were lack of information about degree or duration of aerosol exposures. Thus, further investigation is required into whether SARS-CoV-2 re-positive patients are infectious.

\section{Declarations}

\section{Abbreviation:}

COVID-19: coronavirus disease SARS-CoV-2; PCR: polymerase chain reaction; HCP: healthcare personnel; CDC: Centers for Disease Control and Prevention; ICU: intensive care unit

\section{Acknowledgement: None}

Authors' Contributions: All authors meet the ICMJE authorship criteria.

YO was responsible for organization and coordination of this study. YO, KN, and IG developed the study design. YO and KK performed the formal analysis. HY performed viral cultures. All authors contributed to the writing of the final manuscript. All authors have read and approved the manuscript.

Funding: No funding source 
Availability of data and materials: All data generated or analyzed during this study are included in this published article.

Ethics approval and consent to participate: This study was approved by the ethics committee of Sakai City Medical Center (approved number: 170 , June $10^{\text {th }}, 2020$ ). Written informed consents were obtained from the participates.

Consent for publication: Not Applicable

Competing interests: The authors declare no conflict of interest.

\section{References}

[1] van Doremalen N, Bushmaker T, Morris DH, Holbrook Mg, Gamble A, Williamson BN, et al. Aerosol and surface stability of SARS-CoV-2 as compared with SARS-CoV-1. N Engl J Med. 2020; 283: 1564-1567. [2] Interim U.S. Guidance for Risk Assessment and Public Health Management of Healthcare Personnel with Potential Exposure in a Healthcare Setting to Patients with 2019 Novel Coronavirus. https://www.cdc.gov/coronavirus/2019-ncov/hcp/guidance-risk-assesment-hcp.html

[3] Kang YJ. South Korea's COVID-19 infection status: From the perspective of re- positive after viral clearance by negative testing. Disaster Med Public Health Prep. 2020. doi: 10.1017/dmp/2020/168. [4] Yuan J, Kou S, Liang Y, Zeng J, Pan Y, Liu L. PCR assays turned positive in 25 discharged COVID-19 patients. Clin Infect Dis. 2020 doi: 10.1093/cid/ciaa398.

[5] Ye G, Pan Z, Pan Y, Deng Q, Chen L, Li J, et al. Clinical characteristics of severe acute respiratory syndrome Coronavirus 2 reactivation. J Infect. 2020; 80: e14-17. doi: 10.10106/j.inf.2020.03.001 [6] Wölfel R, Corman VM, Guggemos W, Seilmaier M, Zange S, Muller MA, et al. Virological Assessment of Hospitalized Patients with COVID-19. Nature. 2020; 581: 465-469.

\section{Table}

Table 1. Characteristics of the healthcare personnel and the PPE they were wearing 


\begin{tabular}{|c|c|c|c|c|c|}
\hline No. & Occupation & Age & Wearing PPE & $\begin{array}{l}\text { Lack of } \\
\text { recommended } \\
\text { protection }\end{array}$ & Exposures \\
\hline 1 & Nurse & 20's & $\begin{array}{l}\text { gloves, surgical mask, } \\
\text { eye protection }\end{array}$ & gown & contact \\
\hline 2 & Nurse & 20 's & $\begin{array}{l}\text { gloves, surgical mask, } \\
\text { eye protection }\end{array}$ & gown & contact \\
\hline 3 & ST & 40 's & $\begin{array}{l}\text { gloves, surgical mask, } \\
\text { eye protection }\end{array}$ & gown and N95 mask & $\begin{array}{l}\text { contact and } \\
\text { aerosol }\end{array}$ \\
\hline 4 & Nurse & 40 's & $\begin{array}{l}\text { gloves, surgical mask, } \\
\text { eye protection }\end{array}$ & gown & contact \\
\hline 5 & Nurse & 30 's & $\begin{array}{l}\text { gloves, surgical mask, } \\
\text { eye protection }\end{array}$ & gown & contact \\
\hline 6 & Nurse & 20's & gloves, surgical mask & $\begin{array}{l}\text { gown, eye protection, } \\
\text { N } 95 \text { mask }\end{array}$ & $\begin{array}{l}\text { contact and } \\
\text { aerosol }\end{array}$ \\
\hline 7 & Doctor & 20's & gloves, surgical mask & gown, eye protection & contact \\
\hline 8 & Doctor & 40 's & gloves, surgical mask & $\begin{array}{l}\text { gown, eye protection, } \\
\text { N 95mask }\end{array}$ & $\begin{array}{l}\text { contact and } \\
\text { aerosol }\end{array}$ \\
\hline 9 & PT & 20 's & $\begin{array}{l}\text { gloves, surgical mask, } \\
\text { eye protection }\end{array}$ & gown, N95 mask & $\begin{array}{l}\text { contact and } \\
\text { aerosol }\end{array}$ \\
\hline 10 & PT & 30 's & $\begin{array}{l}\text { gloves, surgical mask, } \\
\text { eye protection }\end{array}$ & gown, N95 mask & $\begin{array}{l}\text { contact and } \\
\text { aerosol }\end{array}$ \\
\hline 11 & Nurse & 40 's & surgical mask & $\begin{array}{l}\text { gloves, gown, eye } \\
\text { protection }\end{array}$ & contact \\
\hline 12 & Nurse & 50 's & $\begin{array}{l}\text { gloves, surgical mask, } \\
\text { eye protection }\end{array}$ & gown, N95 mask & $\begin{array}{l}\text { contact and } \\
\text { aerosol }\end{array}$ \\
\hline 13 & Nurse & 20's & $\begin{array}{l}\text { gloves, surgical mask, } \\
\text { eye protection }\end{array}$ & gown, N95 mask & $\begin{array}{l}\text { contact and } \\
\text { aerosol }\end{array}$ \\
\hline 14 & Nurse & 40 's & gloves, surgical mask & gown, eye protection & contact \\
\hline 15 & Nurse aid & 50 's & $\begin{array}{l}\text { gloves, surgical mask, } \\
\text { eye protection }\end{array}$ & gown & contact \\
\hline
\end{tabular}

Abbreviations: PPE; Personal Protective Equipment, ST; Speech-Language-Hearing Therapist, PT: Physical Therapist The recommended protection was based on the guidance of Centers for Disease Control and Prevention. 